\title{
Crystals, Bubbles and Melt: Critical Conduit Processes Revealed by Numerical Models
}

\author{
M. E. Thomas, J. W. Neuberg and A. S. D. Collinson
}

\section{Abstract}

Understanding how magma moves within a conduit is an important question that is still poorly understood. In particular, estimation of the magma ascent rate is key for interpreting monitoring signals and therefore, predicting volcanic activity. This relies on understanding how strongly different magmatic processes occurring within the conduit control the ascent rate. These processes are controlled by changes in magmatic parameters such as the water content or temperature and understanding/ linking changes of such parameters to monitoring data is an essential step in the use of these data as a predictive tool. The results presented here are from a suite of conduit flow models based on Soufrière Hills Volcano, Montserrat, that assesses the influence of individual model parameters. By systematically changing these parameters, the results indicate that changes in conduit diameter and excess pressure in the magma chamber are amongst the dominant controlling variables. However, the single most important parameter controlling variations in the magma ascent rate is the

M. E. Thomas $(\bowtie) \cdot$ J. W. Neuberg

A. S. D. Collinson

School of Earth and Environment, Institute

of Geophysics and Tectonics, University of Leeds,

Leeds LS12 9JT, UK

e-mail: m.e.thomas@leeds.ac.uk volatile content. Therefore, understanding the processes controlling the volatile content within the conduit system and the outgassing of these volatiles is crucial to understanding and predicting potential unrest or eruption scenarios.

\section{Keywords}

Numerical modelling $\cdot$ Conduit processes Low frequency earthquakes $\cdot$ Magma flow Magma ascent rate

\section{Introduction}

A volcanic conduit provides the pathway for transport of magma and magmatic fluids within a volcano. It is possible to detect both this movement and the occurrence of conduit processes through geophysical monitoring techniques as discussed in Chap. 2 of this book. However, the extent to which changes in magma flow properties affect the data recorded on volcanoes is not well understood. Is it possible that a small change in magma temperature or water content could alter the processes or flow within the conduit enough to be recorded by geophysical monitoring instruments or simple visual observation? What effect does the size of gas bubbles within 
the magma have on the overall flow dynamics, and how big do these changes need to be to alter the eruption style? These types of question are addressed within this chapter in an attempt to identify the crucial parameters that cause changes in observed volcanic behaviour.

We use conduit flow models to analyse the key input parameters that control magma flow properties, such as the magma water content, crystal content and conduit geometry, to assess their relative importance to the overall magma flow dynamics. A list of all input parameters is presented in Table 1 along with the range of values studied. We focus on evolved silicic magmatic systems because of the wealth of relevant monitoring information and previous numerical modelling attempts relating to
Soufrière Hills Volcano, Montserrat-a long lived andesitic dome forming eruption (Sparks et al. 2000; Wadge et al. 2014) and excellent natural laboratory. While these initial models are based on extrusive eruptions, the results of changing the model parameters have the potential to alter the eruption style to either more violent or gentle forms and it is noted that the underlying principles discussed here are applicable to other volcanic systems, including those exhibiting signs of unrest, yet to develop into a full blown eruption. If we can develop the findings presented in this chapter into the creation of threshold levels for recorded geophysical data, it may become possible to begin to predict when a volcano will evolve from a state of unrest to eruption.

Table 1 Parameters used in the reference model and range of parameter variations

\begin{tabular}{|c|c|c|c|}
\hline Symbol/abbreviation & Variable & "Reference" model value & $\begin{array}{l}\text { Range of } \\
\text { modelled values }\end{array}$ \\
\hline- & The melt composition & $\begin{array}{l}\text { Rhyolitic }\left(>71 \% \mathrm{SiO}_{2}\right) \\
\text { (Barclay et al. 1998) }\end{array}$ & See Table 2 \\
\hline$b_{n i}$ & Bubble number density & $10^{10} \mathrm{~m}^{-3}$ (Cluzel et al. 2008) & $10^{7}-10^{11} \mathrm{~m}^{-3}$ \\
\hline$D_{\mathrm{TBL}}$ & $\begin{array}{l}\text { Thickness of thermal boundary layer } \\
\text { over which } T_{\text {diff }} \text { is lost }\end{array}$ & $\begin{array}{l}0.3 \mathrm{~m} \text { (Collier and Neuberg } \\
2006)\end{array}$ & $0.3-0.5 \mathrm{~m}$ \\
\hline$\Gamma$ & Bubble surface tension & $\begin{array}{l}0.06 \mathrm{~N} \mathrm{~m}^{-1} \text { (Lyakhovsky } \\
\text { et al. 1996) }\end{array}$ & $0.05-0.25 \mathrm{~N} \mathrm{~m}^{-1}$ \\
\hline$\chi_{c}$ & Magma chamber crystal volume fraction & 40\% (Barclay et al. 1998) & $40-50 \%$ \\
\hline Ls & Slip length of brittle failure of melt & 0.01 & $0.01-1.0 \mathrm{~m}$ \\
\hline$P_{e}$ & $\begin{array}{l}\text { Excess chamber pressure above } \\
\text { lithostatic }\end{array}$ & $0 \mathrm{MPa}$ & 0-20 MPa \\
\hline$P_{\text {top }}$ & Pressure at conduit exit & $0.09 \mathrm{MPa}$ & $0.09-4.5 \mathrm{MPa}$ \\
\hline$\rho_{c}$ & Average density of crystal assemblage & $\begin{array}{l}2700 \mathrm{~kg} \mathrm{~m}^{-3} \text { (Burgisser et al. } \\
2010 \text { ) }\end{array}$ & $\begin{array}{l}2550-3200 \mathrm{~kg} \\
\mathrm{~m}^{-3}\end{array}$ \\
\hline$\rho_{m}$ & Density of pure melt & $\begin{array}{l}2380 \mathrm{~kg} \mathrm{~m}^{-3} \text { (Burgisser et al. } \\
2010)\end{array}$ & - \\
\hline$T$ & Magma temperature & $1150 \mathrm{~K}$ (Devine et al. 2003) & $1100-1150 \mathrm{~K}$ \\
\hline$T_{\text {diff }}$ & Amount of cooling at conduit wall & $\begin{array}{l}200 \mathrm{~K} \text { (Collier and Neuberg, } \\
2006)\end{array}$ & $100-200 \mathrm{~K}$ \\
\hline$\tau_{s}$ & Melt shear strength & - & $10^{5}-10^{7} \mathrm{~Pa}$ \\
\hline$W_{\%}$ & Initial dissolved water content of magma & $4.5 \mathrm{wt} \%$ (Barclay et al. 1998) & $3-8 \mathrm{wt} \%$ \\
\hline$w, d, r$ & $\begin{array}{l}\text { Variables that define the conduit shape } \\
\text { and size }\end{array}$ & See Fig. 1 & See Fig. 2 \\
\hline
\end{tabular}




\section{The Model}

In order to assess the effect of altering the model parameters, a standard or "reference" model is defined. This reference model is based on data available in the literature that refers to Soufrière Hills Volcano, and is outlined in Fig. 1 and Table 1 . The general dimensions of the modelled conduit, shown in Fig. 1 are inferred from geochemical and observational data from Soufrière Hills Volcano (Barclay et al. 1998; Sparks et al. 2000), placing minimum depth constraints of 5-6 km for the position of the magma chamber and width estimates of $30-50 \mathrm{~m}$ for the conduit.

\subsection{Governing Equations}

Conduit flow is computed with a finite element approach within the code COMSOL Multiphysics ${ }^{\circledR}$, and modelled in an axial symmetric domain space through the compressible formulation of the Navier-Stokes equation:

$$
\begin{aligned}
\rho \frac{\partial \boldsymbol{u}}{\partial t}+\rho \boldsymbol{u} \cdot \nabla \boldsymbol{u}= & -\nabla p+\nabla \cdot\left\{\eta\left[\nabla \boldsymbol{u}+(\nabla \boldsymbol{u})^{T}\right]\right. \\
& \left.-\frac{2}{3} \eta[\nabla \cdot \boldsymbol{u}] \boldsymbol{I}\right\}+\boldsymbol{F}
\end{aligned}
$$

and the continuity equation:

$$
\frac{\partial \rho}{\partial t}+\nabla \cdot(\rho \boldsymbol{u})=0
$$

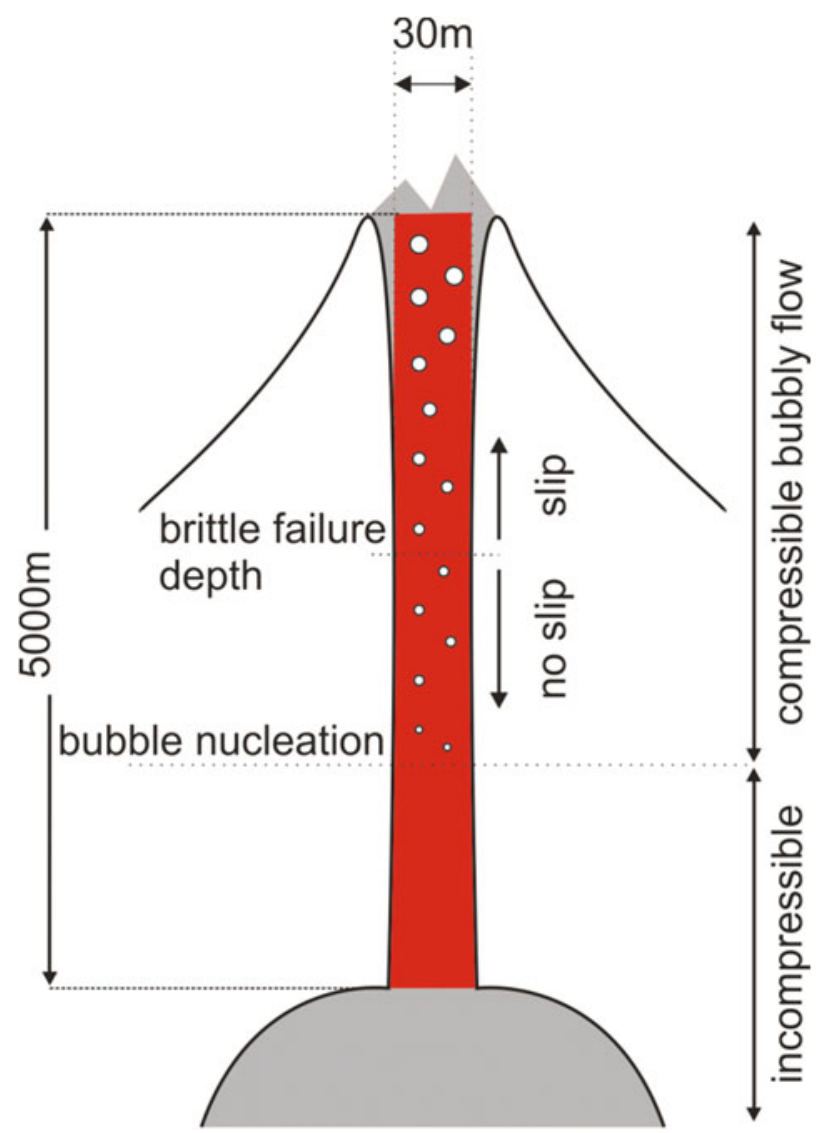

Fig. 1 Cartoon of the modelled volcanic system. Bubble nucleation and brittle failure depth vary with the model parameters considered 
where $\rho$ is density, $\boldsymbol{u}$ the velocity vector, $p$ the pressure, $\eta$ the dynamic viscosity and $\boldsymbol{F}$ the volume force vector (gravity). There is no time dependency in the model as they are solved to a steady state, so the terms $\rho \frac{\partial u}{\partial t}$ and $\frac{\partial p}{\partial t}$ in Eqs. (1) and (2) are neglected.

\subsection{Magma Composition}

The properties of the magma are modelled as the averaged properties of its constituents: melt, crystals and gas. For the reference model, the general composition of the melt is taken as rhyolitic, using the groundmass analysis of Montserrat dome rocks undertaken by Barclay et al. (1998). However, several melt compositions, were ultimately considered to assess the effect of melt composition on the modelled eruption dynamics (Table 2$)$. Crystal content $\left(\chi_{\mathrm{c}}\right)$ and density $\left(\rho_{\mathrm{c}}\right)$ are fixed as we assume a constant temperature and that the conduit ascent times are orders of magnitudes faster than the time required for crystal growth by decompression, meaning only the phenocrysts present in the magma chamber are accounted for and growth of microlites and microphenocrysts is not considered. The expression for the bulk density of the magma is given by:

$$
\rho=\rho_{m} \chi_{m}\left(1-\chi_{g}\right)+\rho_{g} \chi_{g}+\chi_{c} \rho_{c}\left(1-\chi_{g}\right),
$$

where $\chi_{m}$ is the initial fraction of melt $\left(1-\chi_{c}\right)$, $\rho_{\mathrm{m}}$ is the melt density and $\chi_{g}$ is the gas volume fraction (Table 1). For the gas phase, water is assumed as the only volatile species present and the gas density $\left(\rho_{\mathrm{g}}\right)$ is calculated directly from the ideal gas law with the assumption that bubble growth in is equilibrium with the conduit pressure:

$$
p V=n R T
$$

where $V$ is the volume of gas, $R$ the ideal gas constant and $T$ the temperature. The number of moles of water, $n$, is related to density by:

$$
n=\frac{\mathrm{M}}{m},
$$

where $\mathrm{M}$ is the molar mass of water and $m$ is the mass of water present. Thus, combining Eqs. (7) and (8) and considering a unit volume we get:

$$
\rho_{g}=\frac{m p}{R T}
$$

In the reference model, a single magma temperature is used with the exception of the temperature across a thermal boundary layer (TBL) defined adjacent to the conduit wall. A linear temperature drop is applied across the TBL, to simulate the cooling of the magma abutting the country rock in a well-established conduit (Collier and Neuberg 2006). The gas volume fraction $\left(\chi_{g}\right)$ is calculated by determining how much water remains dissolved within the melt at a particular pressure using the solubility of $\mathrm{H}_{2} \mathrm{O}$ in rhyolitic melts presented by Liu et al. (2005). At significant pressures, all the water is dissolved within the melt fraction and $\chi_{g}$ is initially zero. However, as the pressure decreases, water begins to exsolve out of the melt and forms bubbles. The absolute volume of exolved gas ( V) can be calculated from the ideal gas law (4). This absolute volume of gas is then used to calculate the gas volume fraction of the bulk magma constituted by the gas phase.

\subsection{Magma Viscosity-The Contribution of Crystals, Bubbles and Melt}

The bulk magma viscosity $(\eta)$ is determined by first calculating the viscosity of the pure melt phase $\left(\eta_{m}\right)$. This is done using a model for the viscosity of magmatic liquids presented by Giordano et al. (2008), that predicts the viscosity of silicate melts as a function of temperature and melt composition. It is important to note that the composition used in the viscosity model is that of the pure melt phase (rhyolitic) not the overall 
Table 2 Compositions of melt used in the numerical simulations

\begin{tabular}{l|l|l|l|l|l|l|l|l|l}
\hline Composition $^{\mathrm{a}}$ & $\mathrm{SiO}_{2}$ & $\mathrm{Al}_{2} \mathrm{O}_{3}$ & $\mathrm{TiO}_{2}$ & $\mathrm{FeO}$ & $\mathrm{MgO}$ & $\mathrm{MnO}$ & $\mathrm{CaO}$ & $\mathrm{Na}_{2} \mathrm{O}$ & $\mathrm{K}_{2} \mathrm{O}$ \\
\hline $\mathrm{a}$ & 71.41 & 13.58 & 0.28 & 2.78 & 1.64 & 0.13 & 4.86 & 3.73 & 1.6 \\
\hline $\mathrm{b}$ & 76.97 & 11.21 & 0.29 & 1.89 & 0.26 & 0.12 & 1.29 & 4.07 & 2.37 \\
\hline $\mathrm{c}$ & 77.10 & 9.83 & 0.18 & 1.17 & 0.22 & 0.10 & 1.52 & 4.14 & 1.72 \\
\hline $\mathrm{d}$ & 78.66 & 11.20 & 0.39 & 1.93 & 0.30 & 0.10 & 1.48 & 3.57 & 2.38 \\
\hline
\end{tabular}

${ }^{a}$ Compositions determined through, (a) rastered electron microprobe analysis of groundmass (Barclay et al. 1998); (b) Matrix glass composition (Rutherford and Devine 2003); (c) Quartz hosted melt inclusion (Devine et al. 1998); (d) Cameca SX50 microprobe analysis of interstitial glass (Burgisser et al. 2010). All melts are rhyolitic and composition (a) is used in the defined reference model

magma composition. The whole rock composition of recent Soufrière Hills Volcano magma is andesitic (Edmonds et al. 2010), but this includes the contribution of the crystals. The viscosity model is only used to calculate the actual viscosity of the liquid component (the melt), on which the crystals (the solid) have no bearing. When the effect of crystals within the melt is considered, the effective viscosity of the melt (liquid) and crystal (solid) mixture $\left(\eta_{m c}\right)$ increases, and can be represented by the EinsteinRoscoe equation:

$$
\eta_{m c}=\eta_{m}\left(1-\frac{\chi_{c}}{\chi_{c}{ }^{\mathrm{max}}}\right)^{-2.5}
$$

where $\chi_{c}{ }^{\max }$ is the volume fraction of crystals at which the maximum packing is achieved and a commonly adopted value for this is 0.6 (Marsh, 1981), which is used within this study. Although this value was proposed for randomly packed spheres, and it has been shown by Marti et al. (2005) that $\chi_{c}{ }^{\max }$ tends to decrease as the particle (crystal) shape becomes less isotropic. Ishibashi (2009) demonstrated that this value is a good approximation as the effect of particle shape on $\chi_{c}{ }^{\text {max }}$ is offset by effects of size heterogeneity and crystal alignment.

The presence of bubbles also affects the viscosity. If the bubbles within the magma remain un-deformed they act to increase viscosity, whilst if deformed (elongated in the direction of flow), they act to decrease visosity (Llewellin and
Manga, 2005). Whether a bubble is in an un-deformed or deformed state is represented by the capillary number:

$$
\mathrm{Ca}=\frac{\eta_{m} r E}{\Gamma}
$$

where $r$ is the un-deformed bubble radius, $\Gamma$, the bubble surface tension and $E$, a function of the strain rate within the magma flow defined below. If $\mathrm{Ca}>1$ then the bubbles can be considered deformed. The value of $\mathrm{Ca}$ will vary as a function of shear strain rate and elongation strain rate (Thomas and Neuberg 2012), meaning bubbles can be deformed within the model through either shear or extension. To account for strain acceleration or deceleration the dynamic capillary number (Cd) is required (Llewellin and Manga 2005). This compares the timescale over which the bubbles can respond to changes in their strain environment with the timescale over which the strain environment changes. If this value is large, the flow is termed unsteady and the bubbles are unable to deform independently in response to the flow. However, for the models considered here, conditions of unsteady flow are found only in a very small area near the exit of the conduit. Accounting for this within the models resulted in no noticeable change in the derived flow parameters, hence the computation of $\mathrm{Cd}$ is not considered.

Depending on the value of $\mathrm{Ca}, \eta$ is calculated using the suggested 'minimum variation' of Llewellin and Manga (2005): 


$$
\mathrm{Ca}=\left\{\begin{array}{cc}
<1 & \eta=\eta_{m c}\left(1-\chi_{\mathrm{g}}\right)^{-1} \\
>1 & \eta=\eta_{m c}\left(1-\chi_{\mathrm{g}}\right)^{5 / 3}
\end{array}\right.
$$

By assuming the homogeneous nucleation of a number of bubbles in a unit volume of melt as a single event, which is determined experimentally through the initial bubble number density $\left(b_{n i}\right)$ (e.g. Hurwitz and Navon 1994), the bubble radius (Lensky et al. 2002) is given by:

$$
r=\left[\frac{S_{0}{ }^{3} \rho_{m}\left(C_{0}-C_{m}\right)}{\rho_{g}}\right]^{1 / 3},
$$

where $C_{0}$ and $C_{\mathrm{m}}$ are the initial and remaining amount of water dissolved in the melt respectively and $S_{0}$ is the initial size of the melt shell from which each bubble grows. $S_{0}$ is related to the instantaneous bubble number density $\left(b_{n}\right)$ through the expression:

$$
S_{0}^{3}=\frac{3}{4 \pi b_{n}} .
$$

$b_{n}$ is used rather than the initial value $\left(b_{n i}\right)$ because homogeneous nucleation is assumed. Therefore, the bubble number density must remain constant with respect to the volume of the melt fraction in Eq. 3. This also accounts for bubble coalescence and $b_{n}$ is given by:

$$
b_{n}=\frac{b_{n i}}{\chi_{m}}\left[\chi_{m}-\left(1-\chi_{g}\right)\right]
$$

\subsection{Brittle Failure of Melt}

It is now well established that magma, or more specifically the melt component of a magma can fail in a brittle manner (e.g. Goto 1999). This is likely to generate low-frequency (LF) earthquakes (e.g. Neuberg et al. 2006) and effect the overall flow dynamics. In order to account for these effects, it is necessary to define conditions under which the melt may fracture. Shear failure of melt occurs when the shear stress $(\eta \dot{\varepsilon})$ exceeds the shear strength $\left(\tau_{s}\right)$, and has been represented as a brittle failure criterion (e.g. Tuffen et al. 2003):

$$
\frac{\eta \dot{\varepsilon}}{\tau_{s}}>1
$$

where $\dot{\varepsilon}$ is the shear strain rate. This criterion holds true under the assumption that during un-relaxed deformation the accumulation of shear stress in the melt obeys the Maxwell model:

$$
\sigma_{s}=\frac{\eta}{\mu} \frac{\partial \sigma_{s}}{\partial t}=\eta \dot{\varepsilon}
$$

where $\sigma_{\mathrm{s}}$ is the shear stress and $\mu$ the shear modulus.

The magma composition as discussed in Sects. 2.2 and 2.3 is considered without the effects of microlite growth, the reasons for doing so are outlined in Sect. 2.2. However, it is worth noting, that if considered, the influence of microlite growth would possibly increase the bulk viscosity significantly.

\subsection{Boundary Conditions}

Flow within the system is driven by a pressure gradient defined by boundary conditions at the top and bottom of the conduit. The top boundary is set to atmospheric pressure at the altitude of the conduit exit plus any overburden load from an emplaced lava dome. The bottom boundary is set to lithostatic pressure (assuming a homogeneous country rock density of $2600 \mathrm{~kg} \mathrm{~m}^{-3}$ ) plus any imposed overpressure $\left(P_{e}\right)$. Both the top and bottom pressure conditions are held constant throughout the model run. Initial boundary conditions along the length of the conduit are defined as no slip. When brittle failure of melt is considered within a model run, at the regions of the conduit wall where the brittle failure criterion was exceeded, the boundary conditions are changed to a tangential slip velocity $(\Delta \boldsymbol{u})$ defined by:

$$
\Delta \boldsymbol{u}=\frac{1}{\beta} \sigma_{s},
$$


where $\sigma_{s}$ is the tangential shear stress to the conduit wall and the coefficient $\beta$ is a function of the slip length $\left(L_{s}\right)$ :

$$
\beta=\frac{\eta}{L_{s}}
$$

The model is then re-run to account for the effect of changing boundary conditions at the conduit walls. Where this results in an increase in the predicted failure depth, an iterative approach is used and the model is re-run with the new depth until the depth at which brittle failure of the melt stabilises. For the purposes of this study, the failure depth is considered to have converged if the depth increase between iterative runs is less than $10 \%$ of the previous observed increase.

The size and shape of the conduit is also an important factor in influencing the accent rate, so for the purpose of assessing the potential magnitude of this influence, several possible conduit shapes were modelled. While the types of boundary conditions discussed above do not change, the relative locations of the boundaries do (Fig. 2). Case (a) is the simplest geometry change and represents just a change of the conduit radius (r). Case (b) represents a narrowing of the conduit. Case (c) represents a widening of the conduit. The extent to which the geometry of the conduit is changed within the models is discussed further in the next Section.

\section{Critical Conduit Processes}

\subsection{Using Magma Ascent Rates to Assess Model Sensitivity}

The ascent rate is a key parameter in understanding volcanic hazard because it has been directly linked to eruptive behaviour (e.g. Gonnerman and Manga 2007). By gaining a better understanding of which model parameters have the greatest effect on ascent rates, we can achieve an insight into which are the most important parameters controlling explosivity, and the likely severity of the volcanic hazard. For the purpose of comparing the various models we use two velocities, defined as $\bar{V}$ and $V_{2500}$, where $\bar{V}$ is the average accent velocity taken along a vertical profile through the centre of the conduit, and $\mathrm{V}_{2500}$ is the average accent velocity taken along a horizontal profile at a depth of $2500 \mathrm{~m}$ within the conduit.

The ascent rate has also been linked to monitoring data such as seismicity (e.g. Thomas and Neuberg 2012) or deformation (e.g. Zobin et al. 2011), therefore, it is possible to link the changes in model parameters to recorded monitoring data. In addition, there are physically observed variations in ascent rate estimated from a variety of methods, ranging from studying mineral reaction rims around phenocrysts within erupted magma

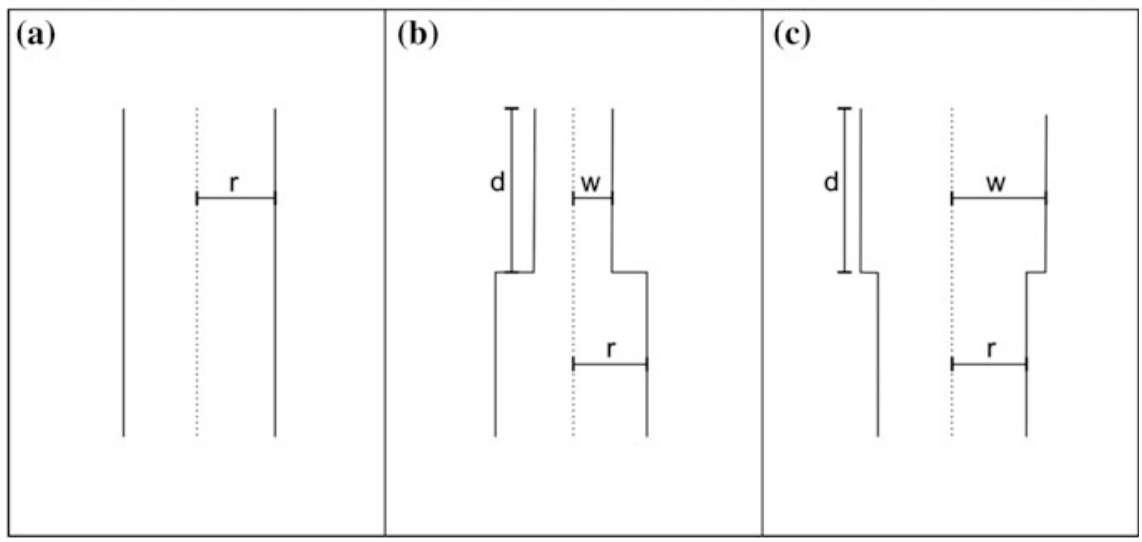

Fig. 2 Schematic diagram of the alternative conduit geometries modelled, showing a constant conduit radius; $\mathbf{b}$ a narrowing conduit and $\mathbf{c}$ a widening conduit 
(Rutherford and Devine 2003) to interpreting lava dome morphology (Sparks et al. 2000). This places constraints on the magnitude of changes to the modelled ascent rate engendered by altering the model input parameters we can consider realistic.

Matching the absolute values of physically observed and calculated ascent rates is currently beyond the scope of the model, however we can use the magnitude of the observed variations to provide upper and lower bounds to the extent to which the model input parameters are varied. Any changes that produce increases in ascent rate greater than two orders of magnitude over the reference model are not considered realistic in this work. This may seem at first an arbitrary discrimination, but there is a good reason that the observed or calculated ascent rates presented in the literature (e.g. Rutherford and Devine 2003; Castro and Gardner 2008) are "slow" $\left(<5 \times 10^{-2} \mathrm{~m} \mathrm{~s}^{-1}\right)$. Faster ascent rates, while likely to exist in nature, would almost certainly result in substantial fragmentation of the magma, making it very difficult to observe or calculate the actual magma ascent rate below the initial point of fragmentation. Fragmentation dynamics are not considered within the current model, hence no valid inferences or conclusions can be gained from studying the model runs that exhibit extremely fast ascent rates.

\subsection{The Critical Model Parameters}

Figure 3 summarises the sensitivity of ascent rate to the different model parameters presented in Table 1. The single parameter (within the modelled ranges) which has the strongest effect on the ascent velocities is the initial dissolved water content of the magma. This parameter affected both $\bar{V}$ and $V_{2500}$ to a large degree. In contrast there are several model parameters which have little effect on the modelled ascent velocities. These include the thermal boundary layer thickness and the temperature drop across it, as well as the bubble number density and bubble surface tension. Modifying the parameters involved in the brittle failure of the melt (magma shear strength and slip length) has a negligible effect on ascent rates and these results have not been plotted on Fig. 3. However, the contribution of the brittle failure of the melt to observed geophysical signals is considered very important, and will be discussed in Sect. 3.3.

It is unsurprising that the group of model parameters that appear to have the greatest effect on the magma ascent velocity, as seen in Fig. 3b (water content, temperature, crystal content, and chemical composition), also have the greatest effect on the magma viscosity (Sect. 2.3). Ultimately, modelling the ascent of magma is a fluid flow problem, and the properties that have the biggest effect on the fluid (magma) properties will have the biggest effect on the overall dynamics of the system. All other parameters have a much smaller direct effect on the fluid properties, and although they may be important to specific small scale magmatic processes when considered in isolation, with respect to the overall magma ascent they appear insignificant. For example, altering the properties of the bubbles within the magma, $b_{n i}$ and $\Gamma$, the effect is to change the shape and the number of bubbles. Previous work has heavily focused on this area (e.g. Llewellin and Magna 2005) but the effect on the overall flow modelled here is minimal. The indication from this is that it is the total volatile content (water in this case) which is available that is more important to governing the overall flow dynamics, rather than how exactly it is stored in the magma. This particular observation is a key point as new estimates from Cassidy et al. (2015) suggest that basaltic South Soufrière Hills magmas (and by extension, possibly other basaltic arc magmas) have the potential to be extremely volatile-rich, containing up to $>6 \mathrm{wt} \%$ $\mathrm{H}_{2} \mathrm{O}$ prior to eruption. Firstly, this validates the use of high initial water contents used in the range of parameters modelled, and secondly, given the range of accent velocities generated within the models as a result of just changing the dissolved water content (the dark blue bars in 


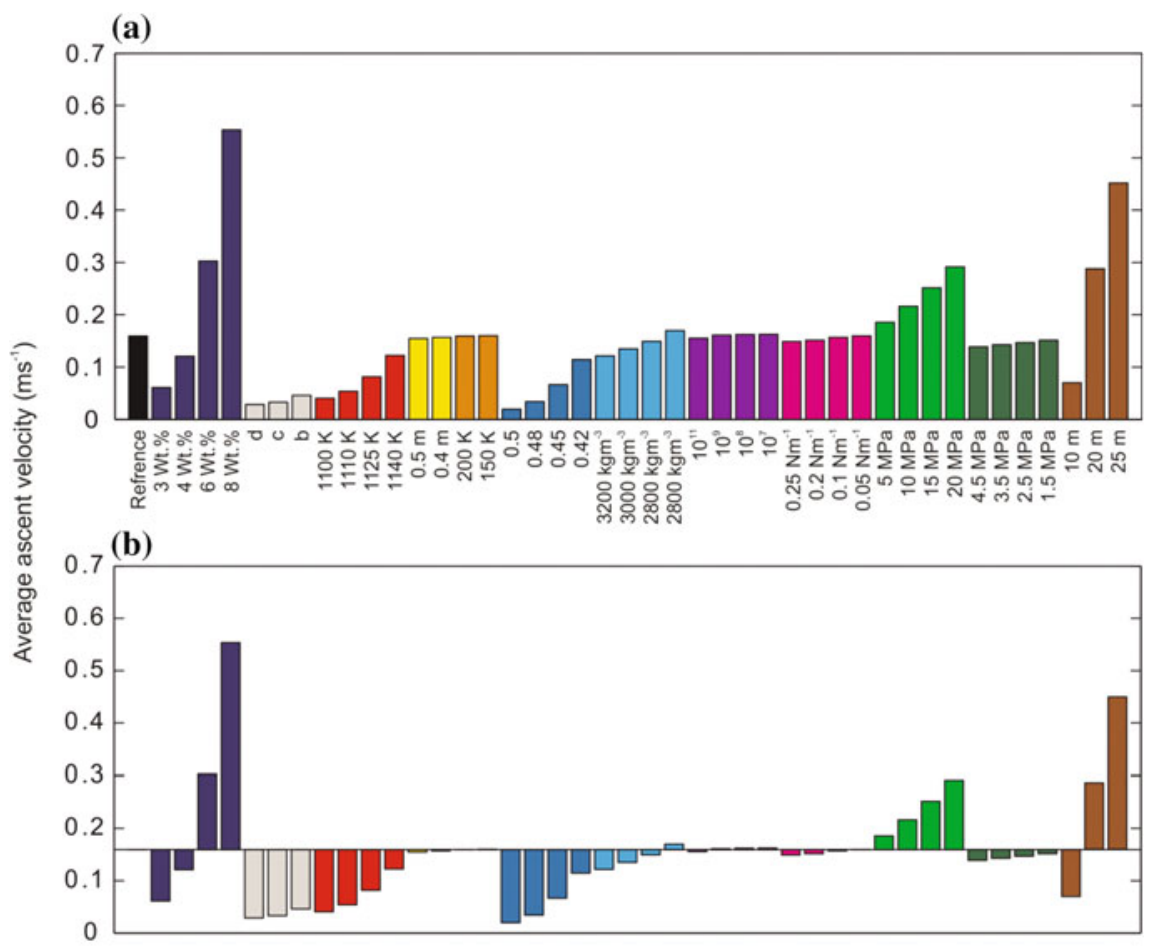

(c)

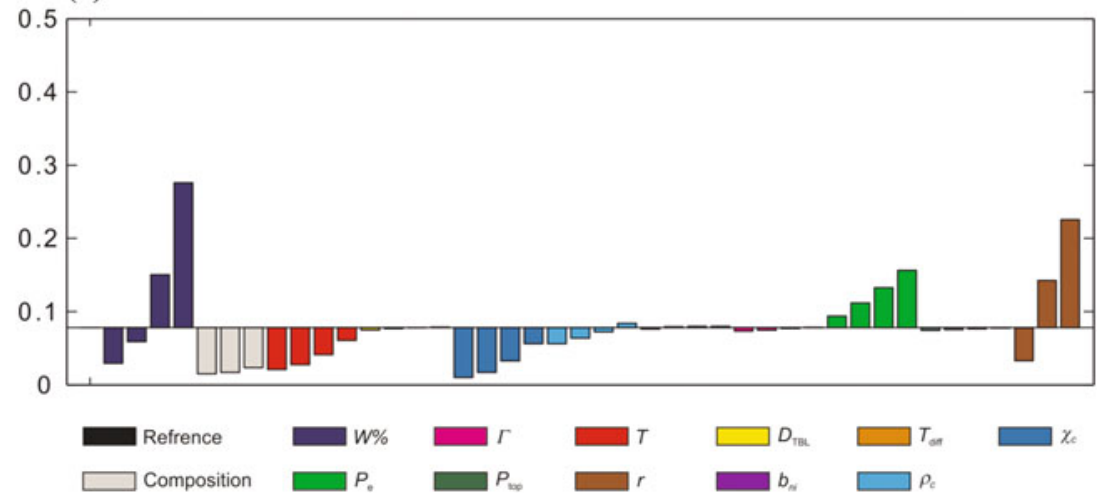

Fig. 3 a The ascent rate, $\bar{V}$ for each value of the parameters altered. The black bar represents the reference model with parameters as listed in Table 1 . b The same data as (a) plotted relative to the reference model, which is represented by the horizontal black line. Parameter

Fig. 3), demonstrates that it is vitally important to obtain an accurate understanding of the magma components at the volcano of interest, rather than assuming "typical" values representative of a broad compositional category.

Outside of water content, temperature, crystal content, and chemical composition, the two changes that caused increases in the ascent rates plot upward from the horizontal line, while parameter changes that caused decreases in ascent rates plot downwards. c $\mathrm{V}_{2500}$ for each value of the parameters altered, plotted relative to the reference model

parameters modelled which have the largest influence on the modelled ascent rate are the chamber overpressure and the conduit geometry. These are particularly important points when considering volcanoes entering periods of unrest following long periods of quiescence. It is problematic to achieve an accurate understanding 
of the magma components highlighted above at all volcanoes under these circumstances due to a likely lack of monitoring (a problem highlighted in Parts 1 and 2 of this book). Unless there has been long-term measurement of deformation occurring at the volcano now exhibiting signs unrest, it will be extremely difficult to estimate any likely overpressures in the chamber, and attempting to define the conduct geometry of a system that has not yet erupted would be almost impossible. It is therefore paramount that as much information as possible of all potentially active volcanic systems is routinely gathered before signs of unrest are detected.

\subsection{Matching Observations- Explosivity and Seismicity}

Although, as previously mentioned, matching the absolute values of physically observed and calculated ascent rates is currently beyond the scope of the model, key to giving the models real significance is determining whether the changes to important parameters highlighted in Sect. 3.1 can be theoretically linked to physical observations at real volcanic systems. Figure 4 shows values of $\mathrm{V}_{2500}$ for all of the modelled parameters in a manner similar to that presented in Fig. 3c, but in this case, the data are plotted relative to a baseline accent value of $0.02 \mathrm{~ms}^{-1}$. This base line value was chosen because it has been highlighted by Rutherford and Devine (2003) as an ascent rate which may indicate a transition between effusive and explosive behaviour. This value has been obtained from quantifying the breakdown of hornblende in ascending magma, and while this technique is not an accurate barometer for defining an exact ascent velocity required for explosive eruptions, the rates calculated for non-explosive eruptive activity at Soufrière Hills volcano between the period of November 1995September 2002 were below this value. Figure 4 shows that several model runs produced ascent rates of $<0.02 \mathrm{~ms}^{-1}$ (by altering the melt composition or $\chi_{c}$ ) and several other runs produced ascent rates very close to this value (by altering $W_{\%}, T$, and conduit geometry), indicating that by altering just single parameters within the system this theoretical threshold of accent rate can be crossed.

Conduit flow is treated as a closed system, so no outgassing is considered in the model, as a result the ascent velocities are overestimated (Thomas and Neuberg 2014). It is therefore predictable that if this process was included, far more of the model runs would result in ascent velocities that straddle the baseline in Fig. 4. This suggests that the ability for the ascent rate within the conduit to fluctuate, either side of values that have been linked to explosive eruptions in response to small changes in the system

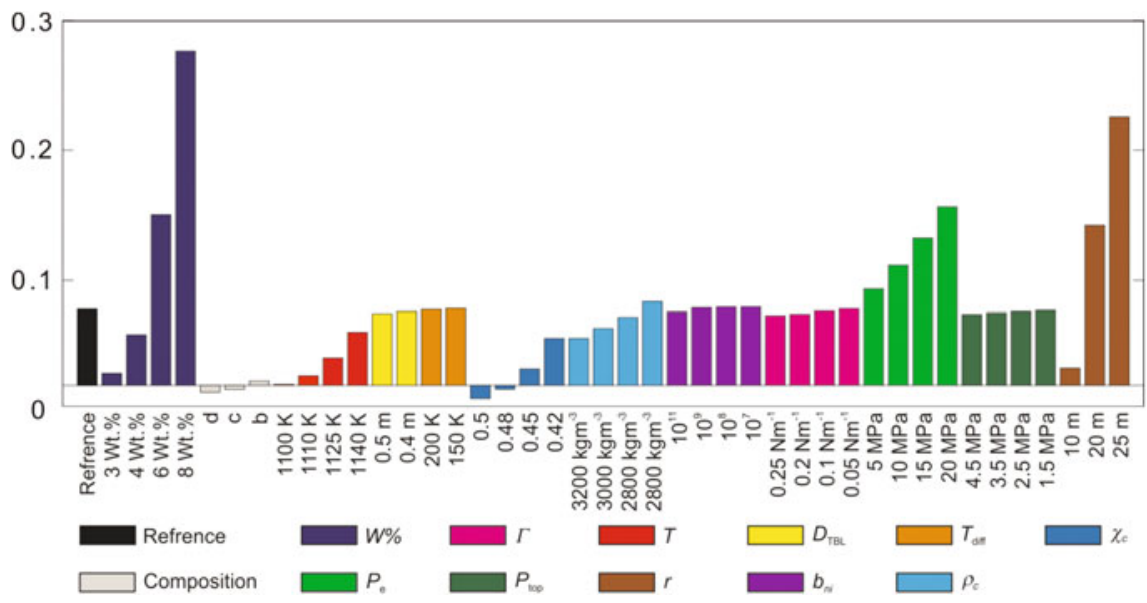

Fig. 4 The ascent rate, $V_{2500}$ for each value of the parameters altered, plotted relative to an ascent velocity of $0.02 \mathrm{~ms}^{-1}$ 
parameters is genuine. The requirement to accurately understand and model outgassing processes (see Sect. 4) is therefore an important capacity that is currently lacking.

One major discrepancy between physical observations and the model is the model results suggested that the brittle failure of the melt (Sect. 2.4) and the related LF seismicity would occur as a shallow process (in agreement with the work of Holland et al. (2011)).The physical observations place the location of this type of seismicity at Soufrière Hills at depths of $\sim 1500$ $\mathrm{m}$ below the conduit exit (Neuberg et al. 2006). This is because under normal conditions the shear stress required to break the melt (Eq. 14) can only be reached where the melt is extremely viscous, which occurs near the surface. In order to reach the higher shear stresses required to break the melt at greater depths, where the viscosity is lower, the shear strain rate $(\dot{\varepsilon})$ needs to increase. Since $\dot{\varepsilon}$ is equal to the lateral velocity gradient within a cylindrical conduit or dyke:

$$
\dot{\varepsilon}=\frac{d v}{d x}
$$

the simplest way to increase $\dot{\varepsilon}$ is to increase the velocity of the magma flowing within the conduit, or reduce the area through which it flows, which since mass must be conserved also has the effect of increasing the flow velocity.

To resolve this discrepancy between model and observations we introduce a constriction within the conduit as a plausible explanation for brittle failure at greater depths. We test its effect within the reference model by including a bottleneck region at a depth of $1500 \mathrm{~m}$, reducing the conduit diameter from 15 to $10 \mathrm{~m}$. This bottleneck is $100 \mathrm{~m}$ in length, which equates to only $1 / 50$ of the total conduit length. Figure 5 shows ascent velocity and shear strain rate profiles from the bottleneck region compared to values from the same location of the conduit in the unmodified reference model. By altering this relatively small region of the conduit, the shear strain rate increases by a factor of four. Crucially, with the exception of small changes in the magma rheology caused by the induced pressure gradients within the bottleneck, the magma viscosity has not been altered. Due to the increased value of shear strain rate the brittle failure ratio (13) will increase by the same factor. By introducing such asperities into the conduit and increasing the strain rate it is possible to drive the brittle fracture of the melt to deeper levels in the conduit that match the location of recorded LF seismicity at Soufrière Hills volcano. This further

(b)

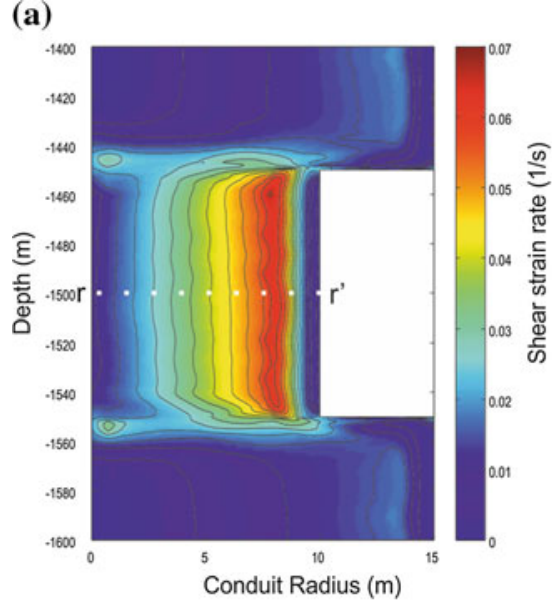

Fig. 5 a Plot of the shear strain rate within a simple bottleneck of $100 \mathrm{~m}$ length at intervals of 0.005 . The values of shear strain rate are seen to be increases over the entire length of the bottleneck. b Cross conduit profiles
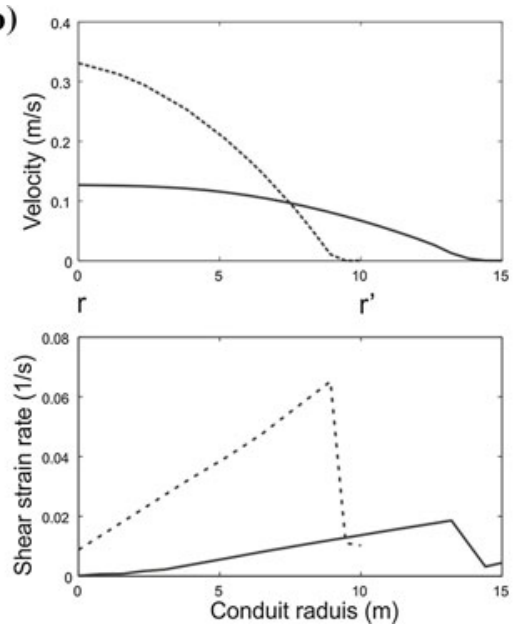

taken at the same depth for velocity and shear strain rate for the case of the unmodified reference model (solid line) and a conduit containing a bottleneck (dashed line) 
emphasises the importance of understanding the possible conduit geometry previously highlighted in Sect. 3.2. This is just one possible solution of generating seismicity deeper in the conduit. Any process that acts to increase the sear strain rate, such as strain localisation between crystals in a magma with a high crystal fraction (as discussed in Chap. 10 of this book) would be a possible explanation.

\section{Pathways for Outgassing}

The role of volatiles has been identified as the primary controlling parameter governing ascent rate within the conduit, but what was not considered was that the gas, once exsolved from the melt has the ability move independently to the melt. This is a commonly assumed process in basaltic systems, but not in silicic magmas of a relatively high viscosity as it is assumed that bubbles of gas cannot rise with significant speed within the magma. However fractures generated by brittle failure of the melt (Sect. 3.3) may provide ideal outgassing pathways for exsolved gas.

The behaviour of this exsolved gas is separated from the problem of magma ascent, and considered independent of any other parameters, through additional numerical modelling in Comsol Multiphysics (Collinson and Neuberg, 2012). In order to consider all possible outgassing pathways, including vertically through the conduit, or laterally through the walls, we model the gas response to brittle failure using a simplistic "block-style" model, with a central conduit and adjacent wall-rocks. Brittle failure is explicitly modelled as an increase in the permeability within narrow regions either side of the conduit. The problem is simplified to considering permeable flow through a static media. Consequently, the equations for Darcy's law (18), and the continuity equation (19) are amalgamated to derive a partial differential equation (20), which is solved for pressure $(P)$ :

$$
\begin{gathered}
\boldsymbol{u}=-\frac{k}{\eta_{g}}(\nabla P+\rho g \nabla z) \\
\frac{\partial}{\partial t}(\rho \varepsilon)+\nabla \cdot(\rho \boldsymbol{u})=0 \\
\frac{\partial}{\partial t}(\rho \varepsilon)+\nabla \cdot \rho\left[-\frac{k}{\eta_{g}}(\nabla P+\rho g \nabla z)\right]=0
\end{gathered}
$$

The gas velocity $(u)$ is then determined by using the pressure gradient within Darcy's law (18).

In contrast, with the models for ascent rate, time dependency is included in this model in order to understand the changes in the system through time, in response to a permeability $(k)$ increase in response to brittle failure at the conduit-wall margin. Due to its abundance in volcanic systems, water is the only volatile considered here. The gas density $(\rho)$ is calculated using the mean molar mass within the ideal gas law (6), and the gas viscosity $(\mu)$ assumed constant at $1.5 \times 10^{-5} \mathrm{~Pa}$ (Collinson and Neuberg 2012).

Bulk permeabilities are set such that the conduit has a higher permeability $\left(10^{-10} \mathrm{~m}^{2}\right)$ than the wallrocks $\left(10^{-12} \mathrm{~m}^{2}\right)$, and initially, the conduit-wall margin is "sealed" with a very low permeability of $10^{-16} \mathrm{~m}^{2}$. The fracturing is initiated at $1500 \mathrm{~m}$, in accordance with measurements by Neuberg et al. (2006), and propagate vertically towards the surface, as an increase in permeability from $10^{-16}$ to $10^{-6} \mathrm{~m}^{2}$.

Figure $6 \mathrm{a}$ shows the initial system, before fracturing, where the gas loss is predominantly vertical, through the conduit. In Fig. $6 \mathrm{~b}$, the fracture zone has propagated vertically up to $700 \mathrm{~m}$ depth. Consequently, the pressure has increased through the conduit and corresponding wall margins where the fractures have developed. This is due to the regions of increased permeability being confined by areas of lower permeability above. Thereby, providing a suitable environment for gas storage, which due to the increased pressurisation, may force exsolved volatiles back into solution within the melt. This change in pressurisation has resulted in a 


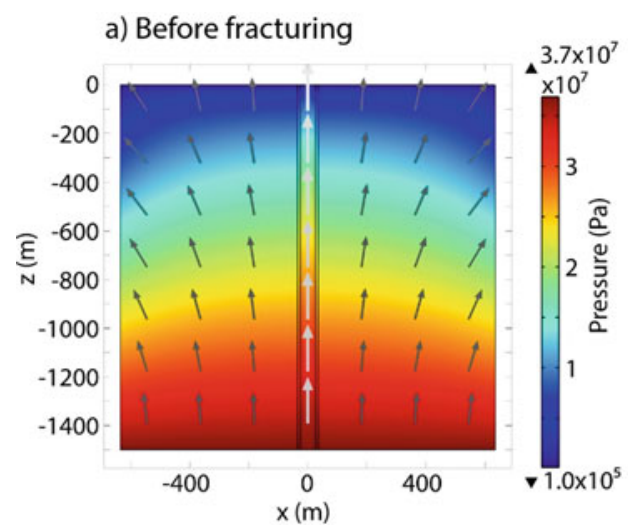

c) Fractures extend 1500-0m depth

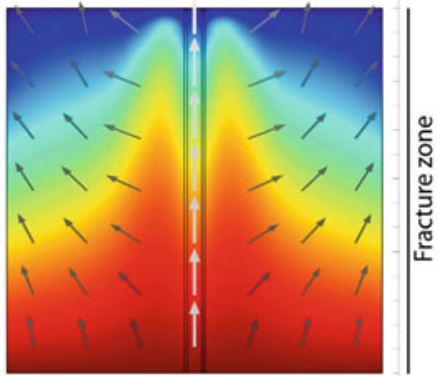

Fig. 6 a The initial system in equilibrium, before fracturing has commenced. b The systems of fractures has propagated upwards to a depth of $700 \mathrm{~m}$. c The fracture zones have reached the surface. $\mathbf{d}$ The system has

corresponding change to the gas velocity pattern, which the lower conduit having a very low gas velocity due to the low pressure gradient. However, at shallow levels, the higher pressure gradient forces a much higher gas velocity towards the surface. On reaching the surface (Fig. 6c), the high permeability fractures result in a decrease in pressure throughout the conduit and a rapid expulsion of the stored gas. Equilibrium conditions resume approximately $4 \mathrm{~h}$ after the fracture zones reached the surface (Fig. 6d). This model shows a propagating fracture zone is an effective mechanism for degassing the conduit and wall margins. A key observation is the possibility for this mechanism to produce periods of cyclic activity which are observed at many silicic volcanoes (e.g. Holland et al. (2011)), which can be directly related to observed degassing patterns or through controlling the ascent rate and the

\section{b) Fractures extend $1500-700 \mathrm{~m}$ depth}

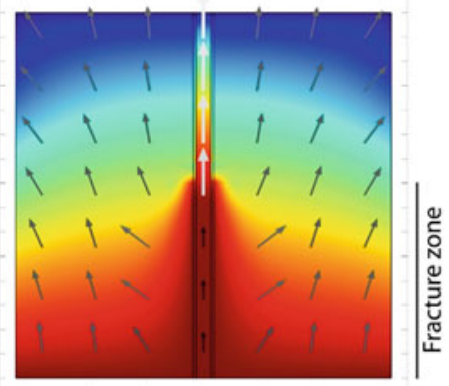

d) After fracturing, in equilibrium

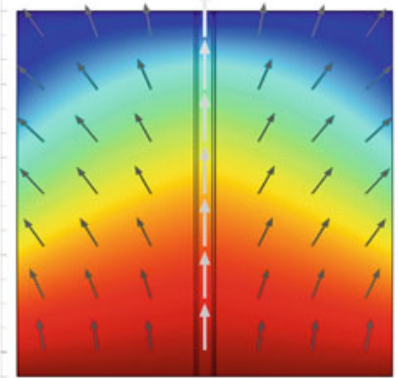

resumed equilibrium. Velocity range of arrows $\left(\mathrm{ms}^{-1}\right)$ : a max: 0.30 , $\min : 1.3 \times 10^{-3} ; \mathbf{b} \max : 0.38$, min: $8.8 \times 10^{-5}$; c max: 0.33 , min: $6.8 \times 10^{-4}$; d $\max$ : 0.30 , min: $9.5 \times 10^{-4}$

associated geophysical signals (e.g. LF seismicity) within the conduit through moderating the amount of gas stored in the system.

\section{Summary and Implications}

In the introduction to this chapter, we asked the question of whether it is possible that small changes in the composition of properties of the magma could cause changes significant enough to be recorded in monitoring data or even visual observations. It is clear that these small changes, particularly when considering changes in the water content or conduit diameter, can have large effects of the ascent velocity of the magma. These effects are large enough that conceivable they could be simply observed as an increased extrusion rate at the surface. At this point however it 
may be too late. If increased extrusions rates are being observed at the surface a critical threshold of ascent rate may have already been surpassed.

More useful would be to observe these potential changes through monitoring before the magma was physically observed to be extruding faster at the surface. Throughout this chapter we have discussed the importance of shear stress, seismicity and outgassing, and it is to monitoring data relating to these processes that we would look for an indication of potential changes.

Increases in ascent velocity may lead to a change in eruption style, but they also potentially cause changes in monitoring data. As discussed in the chapter, any increase in ascent velocity of the magma will cause an increase in the shear stress experience by the magma, and will likely lead to an increase in rate of seismicity, or alter its location. It is now generally accepted that shear stress within the conduit also causes a significant deformation signal (e.g. Neuberg et al. 2018). Any changes in the number or location of low frequency earthquakes, or changes in the near-field deformation around the conduit could therefore be inferred as changes in the magma properties. In addition, the single most important parameter identified within this study was changes in the water content. The fractures generated by the seismicity, as a result of the increases in ascent velocity, have also been shown to be important outgassing pathways. An increase in water content would lead to an increase in volatiles and these would be more easily outgassed along the created fractures. Conceptually, a clear signal of an increase in ascent velocity (and a potential early warning of a change in eruption style) caused by increase in water content of the magma, could be an increase and deepening of low frequency earthquakes, accompanied by an increase in the deformation signal followed by significant outgassing event.

In this chapter we look at a single volcanic setting, but by changing the model parameter these effects could be assessed at any volcano, and regardless of the volcano studied the relative importance of the parameters considered should remain unaltered.
Acknowledgements The authors are grateful for inspiring discussions with Geoff Kilgour (GNS New Zealand) during J. Neuberg's study leave at GNS Research Centre in Wairakei, and contributions to research ideas form former Ph.D. students within the Volcanic Studies Group at the University of Leeds.

\section{References}

Barclay J, Rutherford M, Carroll M, Murphy M, Devine J (1998) Experimental phase equilibria constraints on pre-eruptive storage conditions of the Soufrière Hills magma. Geophys Res Lett 25:3437-3440

Burgisser A, Poussineau S, Arbaret L, Druitt TH, Giachetti T, Bourdier J-L (2010) Pre-explosive conduit conditions of the 1997 Vulcanian explosions at Soufrière Hills Volcano, Montserrat: I. Pressure and vesicularity distributions. J Volcanol Geoth Res 194:27-41

Castro JM, Gardner JE (2008) Did magma ascent rate control the explosive-effusive transition at the Inyo volcanic chain, California? Geology 36:279-282

Collier L, Neuberg J (2006) Incorporating seismic observations into 2D conduit flow modelling. J Volcanol Geoth Res 152:331-346

Collinson ASD, Neuberg JW (2012) Gas storage, transport and pressure changes in an evolving permeable volcanic edifice. J Volcanol Geoth Res 243-244:1-13

Cluzel N, Laporte D, Provost A, Kannewischer I (2008) Kinetics of heterogeneous bubble nucleation in rhyolitic melts: implications for the number density of bubbles in volcanic conduits and for pumice textures. Contrib Miner Petrol 156:745-763

Devine JD, Murphy MD, Rutherford MJ, Barclay J, Sparks RSJ, Carroll MR, Young SR, Gardner JE (1998) Petrologic evidence for pre-eruptive pressuretemperature conditions, and recent reheating, of andesitic magma erupting at the Soufrière Hills Volcano, Montserrat, W.I. Geophys Res Lett 25:3669-3672

Devine JD, Rutherford MJ, Norton GE, Young SR (2003) Magma storage region processes inferred from geochemistry of $\mathrm{Fe}-\mathrm{Ti}$ oxides in andesitic magma, Soufrière Hills Volcano, Montserrat, WI. J Petrol 44:1375-1400

Edmonds M, Aiuppa A, Humphreys M, Moretti R, Giudice G, Martin RS, Herd RA, Christopher T (2010) Excess volatiles supplied by mingling of mafic magma at an andesite arc volcano. Geochem Geophys Geosyst 11:Q04005

Giordano D, Russell JK, Dingwell DB (2008) Viscosity of magmatic liquids: a model. Earth Planet Sci Lett 271:123-134

Gonnermann HM, Manga M (2007) The fluid mechanics inside a volcano. Annu Rev Fluid Mech 39:321-356 
Gotto A (1999) A new model for volcanic earthquake at Unzen Volcano: melt rupture model. Geophys Res Lett 26:2541-2544

Holland ASP, Watson IM, Phillips JC, Caricchi L, Dalton MP (2011) Degassing processes during lava dome growth: Insights from Santiaguito lava dome, Guatemala. J Volcanol Geoth Res 202:153-166

Hurwitz S, Navon O (1994) Bubble nucleation in rhyolitic melts: experiments at high pressure, temperature, and water content. Earth Planet Sci Lett 122:267-280

Ishibashi H (2009) Non-Newtonian behavior of plagioclase-bearing basaltic magma: subliquidus, viscosity measurement of the 1707 basalt of Fuji volcano, Japan. J Volcanol Geoth Res 181:78-88

Lensky NG, Lyakhovsky V, Navon O (2002) Expansion dynamics of volatile-supersaturated liquids and bulk viscosity of bubbly magmas. J Fluid Mech 460:39-56

Liu Y, Zhang Y, Behrens H (2005) Solubility of $\mathrm{H}_{2} \mathrm{O}$ in rhyolitic melts at low pressures and a new empirical model for mixed $\mathrm{H}_{2} \mathrm{O}-\mathrm{CO}_{2}$ solubility in rhyolitic melts. J Volcanol Geoth Res 143:19-235

Llewellin E, Manga M (2005) Bubble suspension rheology and implications for conduit flow. J Volcanol Geoth Res 143:205-217

Lyakhovsky V, Hurwitz S, Navon O (1996) Bubble growth in rhyolitic melts: experimental and numerical investigation. Bull Volc 58:19-32

Marsh B (1981) On the crystallinity, probability of occurrence, and rheology of lava and magma: contributions to mineralogy and petrology. Bull Volcanol 78:85-98

Marti I, Höfler O, Fischer P, Windhab EJ (2005) Rheology of concentrated suspensions containing mixtures of spheres and fibers. Rheol Acta 44:502-512

Neuberg JW, Tuffen H, Collier L, Green D, Powell T, Dingwell D (2006) The trigger mechanism of

Open Access This chapter is licensed under the terms of the Creative Commons Attribution 4.0 International License (http://creativecommons.org/licenses/by/4.0/), which permits use, sharing, adaptation, distribution and reproduction in any medium or format, as long as you give appropriate credit to the original author(s) and the source, provide a link to the Creative Commons license and indicate if changes were made. low-frequency earthquakes on Montserrat. J Volcanol Geoth Res 153:37-50

Neuberg JW, Collinson ASD, Mothes PA, Ruiz CM, Aguaiza S (2018) Understanding cyclic seismicity and ground deformation patterns at volcanoes: Intriguing lessons from Tungurahua volcano. Ecuador, Earth Planet Sci Lett 482:193-200

Rutherford MJ, Devine JD (2003) Magmatic conditions and magma ascent as indicated by hornblende phase equilibria and reactions in the 1995-2002 Soufrière hills magma. J Petrol 44:1433-1454

Sparks RSJ, Murphy MD, Lejeune AM, Watts RB, Barclay J, Young SR (2000) Control on the emplacement of the andesite lava dome of the Soufrière Hills volcano, Montserrat by degassing-induced crystallization. Terra Nova 12:14-20

Thomas ME, Neuberg JW (2012) What makes a volcano tick-A first explanation of deep multiple seismic sources in ascending magma. Geology 40:351-354

Thomas ME, Neuberg JW (2014) Understanding which parameters control shallow ascent of silicic effusive magma. Geochem Geophys Geosyst 15:4481-4506

Tuffen H, Dingwell DB, Pinkerton H (2003) Repeated fracture and healing of silicic magma generate flow banding and earthquakes? Geology 31:1089-1092

Wadge G, Robertson REA, Voight B (eds) (2014) The eruption of Soufrière Hills Volcano, Montserrat from 2000 to 2010. Geol Soc, London, Memoirs, p 39

Zobin VM, Ramirez JJ, Santiago H, Alatorre E, Navarro C (2011) Relationship between tilt changes and effusive-explosive episodes at an andesitic volcano: the 2004-2005 eruption at Volcan de Colima, Mexico. Bull Volc 73:91-99

The images or other third party material in this chapter are included in the chapter's Creative Commons license, unless indicated otherwise in a credit line to the material. If material is not included in the chapter's Creative Commons license and your intended use is not permitted by statutory regulation or exceeds the permitted use, you will need to obtain permission directly from the copyright holder.

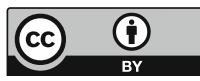

